\title{
Atorvastatin versus rosuvastatin in non-diabetic patients with dyslipidemia: a comparative study
}

\author{
Donepudi Pavan Kumar*, K. Ravishankar
}

Department of Pharmacology, NRI Medical College, Guntur, India

Received: 28 March 2016

Accepted: 04 April 2016

\section{*Correspondence to:}

Dr. Donepudi Pavan Kumar,

Email: pavandonepudi @yahoo.com

Copyright: (c) the author(s), publisher and licensee Medip Academy. This is an openaccess article distributed under the terms of the Creative Commons Attribution NonCommercial License, which permits unrestricted noncommercial use, distribution, and reproduction in any medium, provided the original work is properly cited.

\begin{abstract}
Background: Statins are recognized to be the first line of therapy for lowering cholesterol and have shown to reduce the morbidity and mortality caused by cardiovascular diseases. Atorvastatin and rosuvastatin are potent statins which can efficiently lower the cholesterol and triglyceride levels, we have thus undertaken this study to compare the efficacy of these two statins in nondiabetic patients.

Methods: 150 patients selected for the study, were over 18 years of age with dyslipidemia with no management. Using a randomized computer table, the patients were divided into 2 groups of 75 patients each; group A, who were given atorvastatin $20 \mathrm{mg}$ and group B who were given rosuvastatin $10 \mathrm{mg}$ for 12 weeks. History, and blood tests for fasting blood sugar, hemoglobin A1C, lipid profile such as triglycerides, total cholesterol, HDL cholesterol, LDL cholesterol, urea, creatinine, uric acid, creatine kinase, aspartate aminotransferase, and alanine aminotreasferase. Vitamin $25(\mathrm{OH}) \mathrm{D}$, serum insulin and hs-CRP levels were measured after taking the base line details.

Results: The numbers of women were lesser than that of men. There was a considerable reduction in the triglyceride levels, total and LDL levels in both the groups after 12 weeks of use although between the two groups there was not any significant difference. A slight reduction was seen in the hs-CRP levels and elevation in $V$ it $D_{3}$ levels though this was not very significant due to the lesser duration of the study.

Conclusions: Both atorvastatin and rosuvastatin are equally powerful statins and very effective in reducing the triglyceride and LDL-cholesterol levels. They are also effective in lowering hs-CRP and elevating vitamin D levels.
\end{abstract}

Keywords: Atorvastatin, Rosuvastatin, Statins, Triglycerides, LDL cholesterol

\section{INTRODUCTION}

Accumulation of adipose tissue or obesity is one of the leading concerns in the health care as it is one of the common predisposing factors for cardiovascular diseases in adults and children. ${ }^{1}$ This increases the levels of cholesterol and triglycerides in the body leading to dyslipidemia. Though most often due to fatty diet, Dyslipidemia can also be caused due to prolonged elevation in insulin levels. ${ }^{2}$ It has been estimated that almost every second individual in the United States has abnormal cholesterol values and one third of the population has elevated low density lipoprotein cholesterol levels. ${ }^{3}$ India is becoming a fast killer due to atherosclerosis caused by dyslipidemia. In contrast to the West and other Asians, the prevalence, incidence and hospitalization are 2-4 folds higher at all ages and 5-10 folds above the age of 40 years in India. ${ }^{4}$
Compared to Europeans, Americans \& other Asians the prevalence, incidence, hospitalization and mortality from coronary heart disease in India is $2-4$ folds higher at all ages and 5-10 fold higher in those 40 years of age. Indians are unique in having an atherogenic lipid profile \& lipoprotein. Dyslipidemia, high blood pressure, abdominal obesity and insulin intolerance together constitute a group of cardiovascular risk factors. Their appearance increases the risk of atherosclerosis and cardiovascular disease. ${ }^{5,6}$ The primary goal for therapy is said to be lipid management of the low density protein cholesterol (LDL-C), ${ }^{7}$ although many persons do not achieve the target of low LDL-C levels in spite of lipid lowering therapy. 8,9

Statins are recognized to be the first line of therapy for lowering cholesterol and have shown to reduce the morbidity and mortality caused by cardiovascular 
diseases. ${ }^{10-14}$ They are known to have antioxidant, antiinflammatory effects as well as antithrombic properties. ${ }^{15}$ They are also known to improve endothelial dysfunction and reduce the growth of atherosclerotic plaque. ${ }^{16}$

Atorvastatin and rosuvastatin are potent statins which can efficiently lower the cholesterol and triglyceride levels, ${ }^{17-19}$ though rosuvustatin has been reported to be more effective in various studies especially in type 2 diabetes. We have thus undertaken this study to compare the efficacy of these two statins in non-diabetic patients. $^{20-22}$

\section{METHODS}

This prospective randomized study was conducted over a period of two years at department of Pharmacology at NRI Medical College. 150 patients were selected for the study after thoroughly explaining the procedural techniques and obtaining the Informed consent. All the patients were over 18 years of age with dyslipidemia, but did not meet the goal for LDL-C, according to the European Society of Cardiology (SC) and the European Atherosclerosis Society guidelines for management of dyslipidemia. ${ }^{23}$ Patients with diabetes mellitus, and those on antidiabetic drugs, thyroid or parathyroid dysfunction, any type of malignancy, pregnant women, and breast feeding women were excluded from the study. Patients with more than twice the transaminase levels and three time more creatine kinase levels, those on medications such as those for lipid reduction, vitamin D supplementation or calcium supplementation were also excluded from the study.

Using a randomized computer table, the patients were divided into 2 groups of 75 patients each group A, who were given Atorvastatin $20 \mathrm{mg}$ and group B who were given rosuvastatin $10 \mathrm{mg}$ for 12 weeks. 23 subjects 13 from group A and 10 from Group B showed intolerance to the statins and were excluded. 23 fresh patients were recruited after obtaining informed consent from them and assigned to the groups so as to add up to 75 patients each.

A thorough physical and clinical examination was done on all patients. Demographic details such as age, sex, weight, height were noted. Other details such as waist circumference, blood pressure, both systolic and diastolic were noted and body mass index was calculated. All patients were asked to fast overnight and blood was collected and sent to the biochemistry lab for the detection of fasting blood sugar, hemoglobin A1C, lipid profile such as triglycerides, total cholesterol, HDL cholesterol, LDL cholesterol, urea, creatinine, uric acid, creatine kinase, aspartate aminotransferase, and alanine aminotreasferase. Vitamin $25(\mathrm{OH}) \mathrm{D}$, serum insulin and hs-CRP levels were also measured and all these baseline parameters were noted. Insulin resistance was calculated using the formula:
All statistical analysis was done using SPSS 17.0 software. Paired t test, Mann-Whitney test, Pearson's coefficient were used and a $p$ value of 0.05 was considered as significant.

\section{RESULTS}

Table 1: General characteristics of the patients in both groups.

\begin{tabular}{|c|c|c|}
\hline Parameters & $\begin{array}{l}\text { Group A } \\
(n=75)\end{array}$ & $\begin{array}{l}\text { Group B } \\
(n=75)\end{array}$ \\
\hline Male & 45 & 43 \\
\hline Females & 30 & 32 \\
\hline Age & $58.1 \pm 4.6$ & $57.2 \pm 6.1$ \\
\hline \multicolumn{3}{|c|}{ Body mass index } \\
\hline Base line & $30.1 \pm 1.2$ & $30.4 \pm 0.9$ \\
\hline After 12 weeks & $29.9 \pm 0.9$ & $30.1 \pm 0.8$ \\
\hline \multicolumn{3}{|c|}{ Waist circumference $(\mathrm{cm})$} \\
\hline Base line & $98.8 \pm 2.7$ & $98.2 \pm 2.1$ \\
\hline After 12 weeks & $96.1 \pm 2.2$ & $95.8 \pm 1.9$ \\
\hline \multicolumn{3}{|c|}{ Systolic blood pressure (mmHg) } \\
\hline Base line & $141 \pm 4$ & $140 \pm 6$ \\
\hline After 12 weeks & $136 \pm 6$ & $134 \pm 3$ \\
\hline \multicolumn{3}{|c|}{ Diastolic blood pressure (mmHg) } \\
\hline Base line & $89 \pm 5$ & $88 \pm 4$ \\
\hline After 12 weeks & $80 \pm 2$ & $78 \pm 3$ \\
\hline
\end{tabular}

Out of the 150 patients who completed the study, there was not any significance in the general characteristics between the two groups in terms of age, weight sex body mass index etc. The numbers of women were lesser than that of men, but this also was not a significant parameter which was taken into the account in the study (Table 1).

There was no difference in the different parameters between the two groups at baseline. But, there was a considerable reduction in the triglyceride levels, total and LDL levels in both the groups after 12 weeks of use although between the two groups there was not any significant difference. The base line and after 12 weeks values in both the groups were similar for all the other parameters (Table 2).

\section{DISCUSSION}

The HMG CoA reductase inhibitors are known to be powerful pharmacological agents that are commonly used for the reduction of triglyceride levels and as a result in decreasing the incidence of coronary heart disease. Their use in the treatment of high cholesterol levels has increases rapidly over the years. The reduction of CHD due to the use of statins has been reported to be 25 $60 \% .{ }^{25}$ This success in the statin action on the cholesterol levels has led to the development of newer synthetic molecules such as rosuvostatin. ${ }^{26}$ 
Table 2: Biochemical parameters in the two groups.

\begin{tabular}{|c|c|c|}
\hline Parameters & $\begin{array}{l}\text { Group A } \\
(\mathrm{n}=75)\end{array}$ & $\begin{array}{l}\text { Group B } \\
(n=75)\end{array}$ \\
\hline \multicolumn{3}{|c|}{ Total cholesterol (mg/dl) } \\
\hline Base line & $281.9 \pm 5.1$ & $269.8 \pm 6.7$ \\
\hline After 12 weeks & $176.3 \pm 4.7 *$ & $170.1 \pm 4.9 *$ \\
\hline \multicolumn{3}{|c|}{ HDL cholesterol (mg/dl) } \\
\hline Base line & $59.5 \pm 3.5$ & $61.2 \pm 3.1$ \\
\hline After 12 weeks & $59.2 \pm 3.1$ & $59.4 \pm 2.5$ \\
\hline \multicolumn{3}{|c|}{ LDL cholesterol (mg/dl) } \\
\hline Base line & $195.1 \pm 9.3$ & $187.4 \pm 3.5$ \\
\hline After 12 weeks & $100.9 \pm 12.3 *$ & $98.4 \pm 4.2 *$ \\
\hline \multicolumn{3}{|c|}{ Triglycerides (mg/dl) } \\
\hline Base line & $171.8 \pm 3.0$ & $177.4 \pm 5.3$ \\
\hline After 12 weeks & $112.9 \pm 3.98 *$ & $109.8 \pm 6.9 *$ \\
\hline \multicolumn{3}{|l|}{ Vit $D_{3}(\mathrm{ng} / \mathrm{ml})$} \\
\hline Base line & $20.5 \pm 2.1$ & $23.5 \pm 2.1$ \\
\hline After 12 weeks & $24.1 \pm 1.9$ & $28.1 \pm 6.0$ \\
\hline \multicolumn{3}{|c|}{ Serum glucose (mg/dl) } \\
\hline Base line & $99.1 \pm 11.3$ & $92.5 \pm 3.5$ \\
\hline After 12 weeks & $98.1 \pm 4.2$ & $91.4 \pm 3.1$ \\
\hline \multicolumn{3}{|c|}{ Serum calcium (mg/dl) } \\
\hline Base line & $9.1 \pm 0.6$ & $9.3 \pm 0.9$ \\
\hline After 12 weeks & $9.1 \pm 0.9$ & $9.2 \pm 1.2$ \\
\hline \multicolumn{3}{|l|}{ Insulin $(\mu \mathrm{IU} / \mathrm{ml})$} \\
\hline Base line & $6.4 \pm 0.9$ & $6.5 \pm 0.7$ \\
\hline After 12 weeks & $7.1 \pm 0.6$ & $6.5 \pm 0.3$ \\
\hline \multicolumn{3}{|l|}{ hs-CRP (mg/l) } \\
\hline Base line & $4.4 \pm 1.1$ & $2.9 \pm 0.5$ \\
\hline After 12 weeks & $3.2 \pm 0.7$ & $2.4 \pm 0.9$ \\
\hline \multicolumn{3}{|l|}{ AST (IU/I) } \\
\hline Base line & $26.1 \pm 3.1$ & $22.5 \pm 6.2$ \\
\hline After 12 weeks & $26.9 \pm 2.8$ & $24.1 \pm 2.1$ \\
\hline \multicolumn{3}{|l|}{ ALP (IU/I) } \\
\hline Base line & $25.1 \pm 5.3$ & $23.7 \pm 3.5$ \\
\hline After 12 weeks & $25.7 \pm 3.4$ & $23.1 \pm 1.8$ \\
\hline \multicolumn{3}{|l|}{ CK (IU/I) } \\
\hline Base line & $100 \pm 6.3$ & $109.2 \pm 7.9$ \\
\hline After 12 weeks & $107.5 \pm 7.4$ & $118.8 \pm 3.6$ \\
\hline \multicolumn{3}{|l|}{ HbA1c (\%) } \\
\hline Base line & $5.8 \pm 0.5$ & $5.7 \pm 0.4$ \\
\hline After 12 weeks & $4.3 \pm 0.8$ & $4.7 \pm 0.5$ \\
\hline
\end{tabular}

$* \mathrm{p}<0.001$

High level of LDL-cholesterol is one of the important factors in causing coronary heart disease. $1 \%$ increase of serum cholesterol and $1.5 \%$ increase of serum LDLCholesterol increases the incidence of MI by $2-3 \%{ }^{4}$

We tried to compare and evaluate the efficacy of rosuvastatin and atorvastatin in lowering of cholesterol levels in our area.

The general characteristics in both the groups were similar. The number of males was more than the females in our study with the males accounting for around $60 \%$.
This was in concordance to a study by Jhala et $\mathrm{al}^{27}$ who reported an incidence of males to be around $61 \%$, although a higher incidence of males was found in other studies. $^{11,13,14}$

The prevalence in the higher cholesterol levels were seen more in the age group above 50 years while in the west, the incidence was much later. ${ }^{13,14}$

Along with the high cholesterol levels in these patients, the most common condition to prevail was hypertension. Hypertension as comorbidity was observed in other studies such as the study by Jhala et $a l,{ }^{27}$ Scandinavian study, ${ }^{11}$ Sacks et al. ${ }^{13}$

After 12 weeks of treatment, there was significant reduction in the total cholesterol, LDL cholesterol levels and triglyceride levels from the base line levels. But, there was no difference to be seen between the two groups, though there was a slightly more reduction in the triglyceride levels due to rosuvastatin, though it was not significant. This shows that both the statins were equally efficient in reducing the cholesterol levels. Both the drugs were well tolerated by the patients with no side effects.

Rosuvastatin has shown to improve the triglyceride levels better than atorvastatin, though in our study too, there was a slightly more reduction, though this was not significant. This could be because; in the study by Schwartz ET $\mathrm{al}^{28}$ the treatment was for 24 weeks while in our study it was only for 12 weeks. With a longer period of treatment of the statins, probably a significant difference would have been seen.

Statins are said to have beneficial effects on other levels such as vitamin D Levels, hs-CRP levels and insulin levels. We found a slight lowering of hs-CRP levels and elevation of vit $\mathrm{D}_{3}$ levles by use of these statins, though this difference was not statistically different, though there were studies by other authors where a significant lowering of these levels were observed. ${ }^{29-32}$

\section{CONCLUSION}

Both atorvastatin and rosuvastatin are equally powerful statins and very effective in reducing the triglyceride and LDL-cholesterol levels. They are also effective in lowering hs-CRP and elevating vitamin D levels. Our study found no significant difference in the action and efficacy between these two statins.

\section{Funding: No funding sources}

Conflict of interest: None declared

Ethical approval: The study was approved by the Institutional Ethics Committee 


\section{REFERENCES}

1. Gabay C, Kushner I. Acute-phase proteins and other systemic responses to inflammation. N Engl J Med. 1999;340:448-54.

2. Dyslipidemia. Available at; https://en.wikipedia.org/wiki/Dyslipidemia.

Accessed on 12 March 2016.

3. Roger VL, Go AS, Lloyd-Jones DM, Adams RJ, Berry JD, Brown TM et al. Heart disease and stroke statistics-2011 update: report from the American Heart Association. Circulation. 2011;123(4):e18209.

4. Padmavathi VV, Kambar C, Bano Z, Kurli S, Eswar G, Babu RP. Comparative study of rosuvastatin with atorvastatin in ischemic heart disease patients. IOSR J Dent Med Sci. 2014;13(3):23-9.

5. Brewer HB Jr. New features of the National cholesterol education program adult treatment panel III lipid-lowering guidelines. Clin Cardiol. 2003;26(4 Suppl 3):III19-24.

6. Kim YK. Impact of the metabolic syndrome and its components on pulse wave velocity. Korean J Intern Med. 2006;21:109-15.

7. Boden WE. Therapeutic implications of recent ATP III guidelines and the important role of combination therapy in total dyslipidemia management. Curr Opin Cardiol. 2003;18:278-285.

8. Yood MU, McCarthy BD, Kempf J, Kucera GP, Wells K, Oliveria $\mathrm{S}$ et al. Racial differences in reaching target low-density lipoprotein goal among individuals treated with prescription statin therapy. Am Heart J. 2006;152:777-84.

9. Leibovitz E, Harats D, Gavish D. Efficacy of atorvastatin in treating high risk patients to reach low density lipoprotein-cholesterol goals: the treat to target (TTT-Israel) study. Isr Med Assoc J. 2002;4:407-10.

10. Wood D, De Backer G, Faergeman O, Graham I, Mancia G, Pyörälä K: Prevention of coronary heart disease in clinical practice. Recommendations of the second joint task force of European and other societies on coronary prevention. Eur Heart J. 1998;19:1434-1503.

11. Randomized trial of cholesterol lowering in 4444 patients with coronary heart disease: the Scandinavian Simvastatin Survival Study (4S). Lancet. 1994;344:1383-9.

12. Shepherd J, Cobbe SM, Ford I, Isles CG, Lorimer AR, MacFarlane PW et al. Prevention of coronary heart disease with pravastatin in men with hypercholesterolemia. West of scotland coronary prevention study group. $\mathrm{N}$ Engl J Med. 1995;333:1301-7.

13. Sacks FM, Pfeffer MA, Moye LA, Rouleau JL, Rutherford JD, Cole TG et al. The effect of pravastatin on coronary events after myocardial infarction in patients with average cholesterol levels. N Engl J Med. 1996;335:1001-9.
14. The Long-term Intervention with Pravastatin in Ischaemic Disease (LIPID) Study Group: prevention of cardiovascular events and death with pravastatin in patients with coronary heart disease and a broad range of initial cholesterol levels. $\mathrm{N}$ Engl J Med. 1998;339:1349-57.

15. Tsiara S, Elisaf M, Mikhailidis DP. Early vascular benefits of statin therapy. Curr Med Res Opinion. 2003;19(6):540-56.

16. Pella D, Rybar R, Mechirova V. Pleiotropic effects of statins. Acta Cardiologica Sinica. 2005;21(4):1908 .

17. Watson KE. The Jupiter trial: How will it change clinical practice? Rev Cardiovasc Med. 2009;10(2):91-6.

18. Ukinc K, Ersoz HO, Erem C, Hacihasanoglu AB, Karti SS. Effects of one year simvastatin and atorvastatin treatments on acute phase reactants in uncontrolled type 2 diabetic patients. Endocrine. 2009;35:380-8.

19. Parson HK, Bundy MA, Dublin CB, Boyd AL, Paulson JF, Vinik AI. Pleiotropic effects of rosuvastatin on microvascular function in type 2 diabetes. Diabetes Metab Syndr Obes. 2010;3:19-26.

20. McKenney JM, Jones PH, Adamczyk MA, Cain VA, Bryzinski BS, Blasetto JW et al. Comparison of the efficacy of rosuvastatin versus atorvastatin, simvastatin, and pravastatin in achieving lipid goals: results from the STELLAR trial. Curr Med Res Opin. 2003;19:689-698.

21. Clearfield MB, Amerena J, Bassand JP, García HRH, Miller SS, Sosef FFM et al. Comparison of the efficacy and safety of rosuvastatin $10 \mathrm{mg}$ and atorvastatin $20 \mathrm{mg}$ in high-risk patients with hypercholesterolemia: prospective study to evaluate the use of low doses of the statins atorvastatin and rosuvastatin (PULSAR). Trials. 2006;7:35.

22. Ferdinand KC, Clark LT, Watson KE, Neal RC, Brown CD, Kong BW et al. Comparison of efficacy and safety of rosuvastatin versus atorvastatin in African-American patients in a six-week trial. Am J Cardiol. 2006;97:229-35.

23. Reiner Z, Catpano AL, De Backer G, Graham I, Taskinen MR, European Association for Cardiovascular Prevention \& Rehabilitation, ESC Committee for Practice Guidelines (CPG) 2008,2010, and 2010,-2012, Committees et al. ESC/EAS Guidelines for the management of dyslipidaemias the Task Force for the management of dyslipidaemias of the European Society of Cardiology (ESC) and the European Atherosclerosis Society (EAS). Eur Heart J. 2011;32:1769-818.

24. Mojiminiyi OA, Abdella NA. Effect of homeostasis model assessment computational method on the definition and associations of insulin resistance. Clin Chem Lab Med. 2010;48:1629-34.

25. Knoop RH. Drug treatment of lipid disorders. N Engl J Med. 1999;341(7):498-511.

26. Carswell $\mathrm{Cl}$, Plosker GL, Jarvis B. Rosuvastatin. Drugs. 2002:62(14):2075-85. 
27. Jhala CI, Shah VA Shah UV, Dafda JD. Patterns of cardiac disorders \& Epidemiology of Coronary artery disease in Urban population of Ahmedabad. J Indian Med Assoc. 1999;97(6):237-40.

28. Schwartz GG, Bolognese MA, Tremblay BP, Caplan R, Hutchinson H, Raza A et al. Efficacy and safety of rosuvastatin and atorvastatin in patients with hypercholesterolemia and a high risk of coronary heart disease: a randomized, controlled trial. Am Heart J. 2004;148(1):H1-9.

29. Ott C, Raff U, Schneider MP, Titze SI, Schmieder RE. 25-hydroxyvitamin D insufficiency is associated with impaired renal endothelial function and both are improved with rosuvastatin treatment. Clin Res Cardiol. 2013;102:299-304.
30. Yavuz B, Ertugrul DT, Cil H, Ata N, Akin KO, Yalcin AA et al. Increased levels of 25 hydroxyvitamin D and 1,25-dihydroxyvitamin D after rosuvastatin treatment a novel pleiotropic effect of statins. Cardiovasc Drugs Ther. 2009;23:295-9.

31. Pérez-Castrillón JL, Vega G, Abad L, Sanz A, Chaves J, Hernandez $G$ et al. Effects of atorvastatin on vitamin D levels in patients with acute ischemic heart disease. Am J Cardiol. 2007;99:903-5.

32. Sathyapalan T, Shepherd J, Arnett C, Coady AM, Kilpatrick ES, Atkin SL. Atorvastatin increases 25hydroxyvitamin D concentrations in patients with polycystic ovary syndrome. Clin Chem. 2010;56:1696-700.

Cite this article as: Donepudi PK, Ravishankar K. Atorvastatin versus rosuvastatin in non-diabetic patients with dyslipidemia: a comparative study. Int J Basic Clin Pharmacol 2016;5:656-60. 